\title{
Disinfection of Archived Material by Radiation Processing Technology Keeping the Material Integrity
}

\author{
Md Kamruzzaman Pramanik*, Abdul Bathen Miah and Md Khorshed Alam \\ Institute of Food and Radiation Biology, Atomic Energy Research Establishment, Bangladesh Atomic Energy Commission \\ Dhaka, Bangladesh
}

\begin{abstract}
The aim of the study was to preserve paper-based archived material for a long period of time using ionizing radiation/nuclear technique. To conduct this research, old note-pad samples were selected as tentative archived material. Samples were prepared and irradiated at a series of radiation doses e.g. 0, 2.0, 4.0, 6.0, 8.0, 10.0 and $14.0 \mathrm{kGy}$ at a dose rate of $12.8 \mathrm{kGy} / \mathrm{h}$ from panaromic Batch type $80 \mathrm{kCi}{ }^{60} \mathrm{Co}$ source. After irradiation, different quality parameters such as microbiological (Total Viable Bacterial Count, Total Fungal Count), mechanical (Tensile Strength, Percent of Elongation at Break and Elastic Modulus) and color properties (L-value, a-value and b-value) of the samples were assessed to observe the immediate effect of ionizing radiation on these properties. Results showed that the total bacterial count of unirradiated (control) paper were $4.0 \times 10^{2} \mathrm{cfu} / \mathrm{g}$ and radiation dose of $2.0 \mathrm{kGy}$ was enough to eliminate the microbial load completely. Among mechanical properties, tensile strength (TS) of unirradiated sample was 16.23 MPa and it was gradually increased as the dose increased and finally reached upto 18.99 MPa at a dose of $14 \mathrm{kGy}$ causing the TS-change above significant level $(p<0.05)$. Though changes of percent of elongation at break (EB) due to irradiation was insignificant, elastic module (EM) increased as the radiation dose increased gradually. EM of non irradiated sample was $381.85 \mathrm{~N} / \mathrm{m}^{2}$ and it started changing significantly from $6.0 \mathrm{kGy}$ and finally reaches upto $477.03 \mathrm{~N} / \mathrm{m}^{2}$ at $14.0 \mathrm{kGy}$. Results showed that L-value of colour parameter changed very slightly though a and b-value changed significantly from $6.0 \mathrm{kGy}$. From these findings it can be inferred that a radiation dose of $4.0 \mathrm{kGy}$ might be used to conserve the cultural heritage including valuable paper-based archived materials.
\end{abstract}

\section{Introduction}

Conservation of different national as well as world cultural heritage is very important task to represent the national identity and to know the cultural practices of past time. Many of the cultural heritages are made of paper, wood or textiles which are cellulose/ protein-based that are prone to be attacked by cellulolytic/ proteolytic molds and bacteria under favorable conditions. This situation not only brings risks to human health by mold contamination but also causes the decay of valuable publications like ancient books and rare documents ${ }^{1}$. Paper and paperboard are also used as archived materials which are sheet materials made from an interlaced network of cellulose fibers derived from wood by using sulfate and sulfite. The fibers are then pulped and/or bleached and treated with chemicals such as slimicides and srengthening agents to produce paper products ${ }^{2}$. In addition to cellulolytic bacteria, insects such as silverfish, crickets, cockroaches and booklice deteriorate the valuable archived materials and people have to use insecticides which on the otherhand cause detrimental effect to the users ${ }^{3}$. Besides deterioration of the materials there is also a risk for occupational health as they can cause infection (mycoses) and allergic reaction and mycotoxicosis. Few decades back, ethylene oxide (EO) was used to disinfect these archived materials with some drawbacks e.g., toxicity, slow releasing of EO from treated material, significant residue etc. Moreover, it has been reported that EO-treated object become more prone to reinfestation. A promising alternative treatment of preservation is the use of gamma radiation $^{4-6}$. Recently, gamma radiation from cobalt-60 source has been reported to be applied to disinfect those types of materials and good result has been obtained applying a limited dose of radiation i.e, 10-15.0 kGy, though very high doses (>60 $\mathrm{kGy}$ ) caused significant changes e.g., conferred yellowish colour to papers. Although several recent studies have described the application of gamma irradiation for controlling fungal growth on papers, opinions differ regarding the optimal radiation dose applied to paper and its effect on the paper integrity ${ }^{7-9}$. However, the wider application of this nuclear technique requires extensive research which will ensure the quality of irradiated archived and heritage material without any undesirable changes in their decorative and functional properties. Therefore, importance for preservation of these heritages and archived materials has become a key issue. Like other countries, Bangladesh has also many national heritages that are made of paper, textile, wood, leather, parchment, fur, silk etc. which are prone to cellulolytic or proteolytic fungal and bacterial attack. Moreover, humidity percentage of Bangladesh

*Corresponding author:

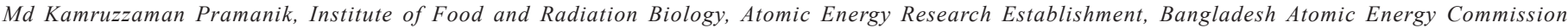
Dhaka,BangladeshEmail: kpramanik2003@yahoo.com) 
also favours biological attack on those items. Therefore, conservation of items for long time is of great importance and is also very essential to conserve our heritages including document archives.

Paper and paper products are mainly degraded due to internal and external causes. Internal cause of degradation can reside in the paper itself that is the composition of the paper e.g. wood lignin, alum, rosin, chlorine. External degradation can be mechanical, environmental, chemical or biological. There are three environmental factors that affect the conservation of paper e.g. humidity, temperature and light. An excess of moisture softens the size and leads to the formation of acids derived from salts and other products used in the manufacture of paper or ink. Sudden and frequent changes in temperature and humidity subject paper to great strains that may rupture its fabric. Most potent destroyers of paper are rodents, insects and microorganisms. Microorganisms (fungi and bacteria) soften paper in the areas they invade, break up the surface sizing, and release pigments in the course of their metabolic cycle. Choi et al. ${ }^{12}$ found that radiation treatment disinfected the Korean traditional paper Hanji efficiently without changing its properties and that this treatment could be used to prevent the damage of Korean ancient archives by molds and fungi.

Therefore, using this facility, there is a scope to carry out some research work for increasing longevity of these items and develop suitable radiation processing technique (e.g., with respect to radiation processing or dose selection) for longtime preservation of these items without losing their fundamental and decorative properties.

The objective of the present study was to develop a suitable method for disinfection of archived materials and cultural heritage artifacts for their conservation using nuclear technique with the existing $90 \mathrm{kCi}$ cobalt-60 gamma irradiator. Considerations for the study was focused on the control of microbiological bioburden and mechanical properties of the treated objects.

\section{Materials and Methods}

Old paper documents were used from the Institute of Food and Radiation Biology, Atomic Energy Research Establishment, Savar, Dhaka, Bangladesh. Paper sheets of the thickness 0.09-0.1 mm, were cut in 10.0 x $1.0 \mathrm{~cm}$ size, packed in sterile polyethylene pouches and sealed before radiation treatment. Analysis of all irradiated and unirradiated samples were carried out for mechanical (Tensile strength, Elongation at break), Colour (LAB) and microbiological parameters. All tests were analysed in numbers of fives.

\section{Irradiation of samples}

Doses were applied to the samples at room temperature from the Co-60 gamma irradiator source (Located at Atomic Energy Research Establishment, Institute of Food and Radiation Biology, Dhaka, Bangladesh) by calibrating with dose and time basis on central distance from source to sample where these were placed.
Irradiation in the dose range of $0,2,4,6,8,10$ and $14 \mathrm{kGy}$ were applied to the packaged paper samples at dose rate $12.8 \mathrm{kGy} / \mathrm{h}$ from panaromic Batch type $80 \mathrm{kCi}{ }^{60} \mathrm{Co}$ source (BRIT, INDIA). Irradiaton dose was measured using ceric-cerous dosimetry system $^{11}$.

\section{Mechanical Properties}

Tensile Strength (TS) and percent of Elongation at break (EB) of the papers were measured by ASTM methods ${ }^{12}$. The load capacity was $500 \mathrm{~N}$, efficiency was within $\pm 1 \%$. The crosshead speed was $2 \mathrm{~mm} / \mathrm{min}$. Gauze length was $40 \mathrm{~mm}$. The Tensile strength (TS), percent of Elongation at break (EB\%) and elastic modulus (EM) were measured by the Following equations.

Tensile Strength $(\mathrm{TS}, \mathrm{MPa})=\frac{\text { Load }}{\text { Thickness } \times \text { Width }}$
Percent Elongation at Break $(\mathrm{EB}, \%)=\frac{\text { Elongation at Rupture } \times 100}{\text { Initial gage length }}$
Young's Modulus $\left(\mathrm{EM}, \mathrm{N} / \mathrm{m}^{2}\right)=\frac{\text { Stress }}{\text { Strain }}$

\section{Colour Measurement}

Color Measurements were carried out by Chromameter CR 400 of Konica Minolta Inc (Japan) and reported in simple Lab format. Colour measurements were recorded as $\mathrm{L}^{*}, \mathrm{a}^{*}$ and $\mathrm{b}^{*}$ value. ( $\mathrm{L}^{*}=$ lightness (white $\mathrm{L}=100$ to black $\mathrm{L}=0$ ); $\mathrm{a}^{*}=$ ranging from red $(+)$ to green $(-)$, positive $a$ is red and negative is green; $b^{*}=$ yellow $(+)$ to blue (-); positive $b$ is yellow and negative $b$ is blue).

\section{Microbiological Analysis}

For microbiological analysis, the polyethylene pouches were cut and samples were dispensed aseptically to sterilized normal saline $(0.89 \%$ sodium chloride solution). The total viable aerobic plate count was determined by standard plate count on Difco nutrient agar using decimal dilution technique followed by pour plating, after incubation at $37^{\circ} \mathrm{C}$ for $24 \mathrm{~h}$. Microbial counts were expressed as colony forming unit per gram $(\mathrm{cfu} / \mathrm{g})^{6}$. Total mold counts were determined using Potato Dextrose Agar with incubation at $30^{\circ} \mathrm{C}$ for 48 hours.

\section{Statistical Analysis:}

For each measurement, five samples of same treatment were tested. Statistical analysis was carried out by MS Excel. Student's Ttests were performed to assess whether the means of irradiated samples were statistically different from that of non-irradiated samples. Differences between means were considered to be significant when $\mathrm{p}<0.05$ assuming unequal variance.

\section{Results and Discussion}

Total Bacterial Count (TBC) and Total Fungal Count (TFC) were determined to observe the overall microbial load in notepad samples. Results showed that TBC in non-irradiated sample was $4.0 \times 10^{2} \mathrm{cfu} / \mathrm{gm}$ and irradiation with the minimum selected dose 
i.e., $2.0 \mathrm{kGy}$ was sufficient to completely eliminate the bacterial count (Fig. 1). Fungal count was found nil in both treated and non-treated samples. Since only the dose of $2.0 \mathrm{kGy}$ completely destroyed all living microbial cells, spore forming microorganisms was supposed to be absent in the samples posing the less risk of deterioration.

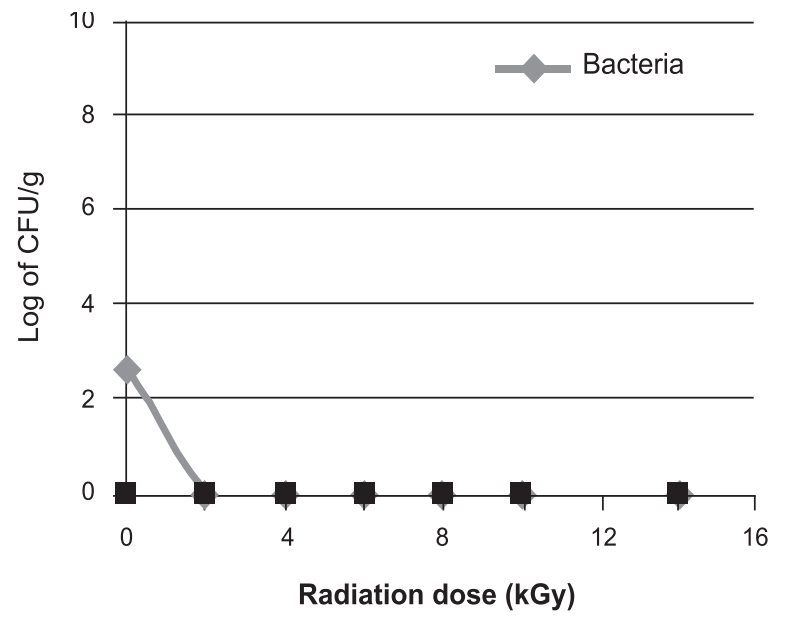

Figure 1. Radiation sensitivity of associated microflora of the paper sheets.

Some mechanical properties of the notepad samples were analyzed to determine whether any unwanted changes occurred in the sample as an effect of radiation. Tensile Strength (TS) increased gradually as the radiation dose increased. Initial TS of control sample was 196.23 MPa and after irradiation with 2.0, 4.0, 6.0, 8.0, 10.0 and $14.0 \mathrm{kGy}$ (Fig. 2), TS increased to 16.91, 17.41, $17.76,17.82$ and $18.99 \mathrm{MPa}$, respectively. Treatment with the dose of $10.0 \mathrm{kGy}$ started rendering a change in TS value above the significant level $(\mathrm{P}<0.05)$. Percent of Elongation at Break (EB) was not changed significantly due to radiation treatment at any dose. Elastic Modulus (EM) increased gradually as the radiation dose increased. Initial EM of the control sample was $381.85 \mathrm{~N} / \mathrm{m}^{2}$

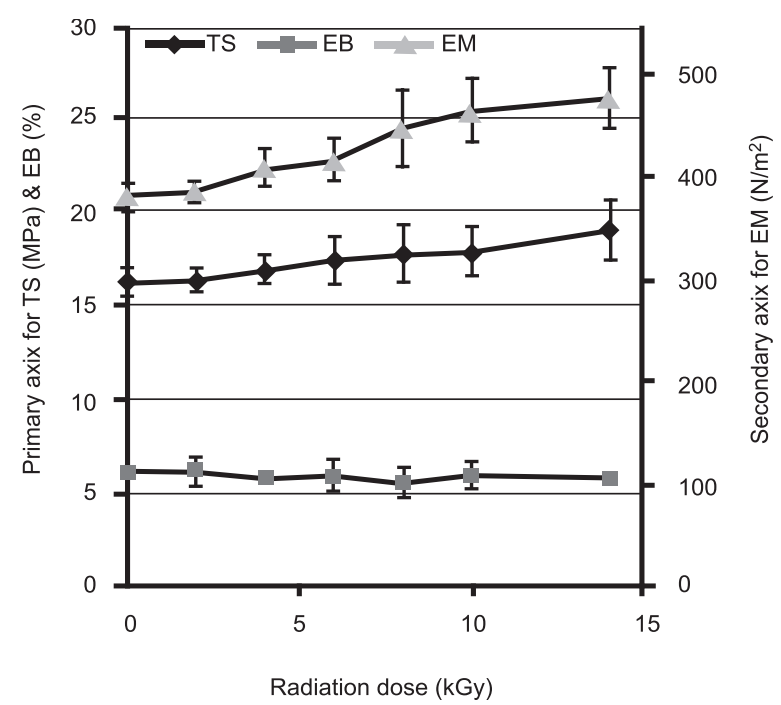

Figure 2. Tensile strength, percent of elongation at break and elastic modulus of the paper sheets. and radiation treatment with the doses of 2.0, 4.0, 6.0, 8.0, 10.0 and $14.0 \mathrm{kGy}$ changed the EM to $386.64,408.22,416.96,447.45$, 464.06 and $477.03 \mathrm{~N} / \mathrm{m}^{2}$ respectively. Statistical analysis showed that the EM value began to change significantly with the dose $4.0 \mathrm{kGy}$. irradiated paper sheets.

Different colour properties (L, a and b-value as described in material and method section) were also examined in the irradiated sample and compared with that of control sample. Though the Lvalue slightly decreased with increasing the radiation dose, no significant changes occurred throughout the radiation treatments (Fig. 3). The initial L-value of control sample was 74.56. After irradiation with 2.0, 4.0, 6.0, 8.0, 10.0 and $14.0 \mathrm{kGy}$, L-value decreased to $73.52,72.82,72.65,72.91,72.89$ and 72.87 respectively. However a and b-value also decreased gradually as the radiation dose increased and no significant changes occurred up to the radiation dose of $4.0 \mathrm{kGy}$.

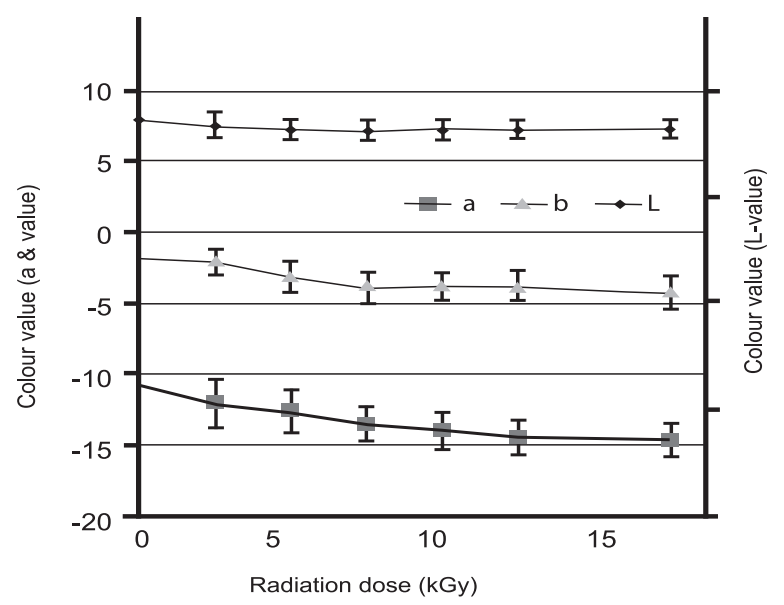

Figure 3. Hunters color values of paper sheets after gamma irradiation at different doses. L means lightness, a means redness, and $b$ means yellowness.

$\mathrm{D} \times$ Almeida et $\mathrm{al}^{13}$ tested the integrity of irradiated paper materials and up to $15 \mathrm{kGy}$ and no significant changes were detected in respect of tensile index, brightness and colour. Although biodeterioration of paper products is dependent on the raw materials and the processing methods, but the findings of the present study is almost similar to that carried out by $\mathrm{D} \times$ Almeida et $\mathrm{al}^{13}$. From the overall findings it was deduced that ionizing radiation treatment of archived material not only destroyed the harmful deteriorating microorganisms but also improve some desirable mechanical properties along with a negligible compensation in colour properties. A radiation dose of $4.0 \mathrm{kGy}$ is recommended as the minimum dose for preservation of paperbased archived materials.

\section{References}

1. Tomazello MGC \& Wiendl FM. 1995. The applicability of gamma radiation to the control of fungi in naturally contaminated paper. Restaurator. 16: 83-99.

2. Marsh K \& Bugusu B. 2007. Food packaging-Role, materials, and environmental issues. J. Food Sci. 72: 1-17.

3. Odegaard N \& Sadongei A. 1992. Old poisons new problems. pp5-6. Rowman \& Littlefield Publishers Inc. New York, Oxford. 
4. Pointing SB, Jone EBG \& Jones AM. 1998. Decay prevention in waterlogged archaeological wood using gamma irradiation. Int. Biodeterior. Biodegradation 42: 17-24.

5. Magaudda, G. 2004. The recovery of biodeteriorated books and archive documents through gamma radiation: some considerations on the results achieved. J. Cultural Heritage 5: 113-118.

6. Adamo M, Giovannotti M, Magaudda G, Plossi-Zappala M, Rocchetti F \& Rossi G. 1998. Effect of gamma rays on pure cellulose paper as a model for the study of a treatment of "biological recovery" of biodeteriorated books. Restaurator. 19: 41-59.

7. Hanus J. 1985. Gamma radiation for use in archives and libraries. Abbey Newsl. 9: 34-36.

8. Gonzalez ME, Calvo AM \& Kairiyama E. 2002. Gamma radiation for preservation of biologically damaged paper. Radiat. Phys. Chem. 63: $263-265$.
9. American Standard Testing Method (ASTM). 1995. AST rd M. 1995a. D8.

10. Gerard J, Berdell RF \& Christine LC. 2004. Microbial growth. In Microbiology an Introduction. pp. 173-175. Pearson Education Pte. Ltd., Singapore.

11. Manual of Food Irradiation Dosimetry. 1977. Technical Report Series No. 178, pp89-102. Vienna: IAEA.

12. Choi J, Chun YJ, Kang DI, Lee KS \& Lee JW. 2012. Effect of radiation on disinfection and mechanical properties of Korean traditional paper. Hanji. Radiation Physics and Chemistry 81: 10511054.

13. D $\times$ Almeida MLO, Barbosa PSM, Boaratti MFG \& Borrely SI 2009 . Radiation effects on the integrity of paper. Radiation Physics and Chemistry. 78: 489-492. 